\title{
Transición del pediatra al internista en fibrosis quística
}

\section{Transition from the pediatrician to the internist in cystic fibrosis}

SoniA RESTREPo, MD.

La fibrosis quística es la enfermedad genética más frecuente en la raza caucásica, con una prevalencia de 1 por cada 2.500 recién nacidos vivos en el Norte de Europa (1). En Colombia se estima una incidencia menor; sin embargo, existe un subregistro de la enfermedad como sucede en otros países Latinoamericanos (2, 3). La fibrosis quística se caracteriza por enfermedad pulmonar progresiva $\mathrm{y}$ compromiso gastrointestinal variable, como resultado de la mutación del gen de la CFTR (proteína reguladora de la conductancia transmembrana de la fibrosis quística), de la cual hasta el momento se han encontrado aproximadamente 1.900 mutaciones, la más frecuente la DF508 (4).

Así mismo, la atención de los pacientes con fibrosis quística representa un reto para las diferentes especialidades pediátricas que día a día se encargan de su tratamiento y cuidado. En los últimos años se ha logrado un aumento de la supervivencia de estos pacientes gracias al mejor acceso a los servicios de salud, al diagnóstico temprano y a la disponibilidad de nuevas estrategias terapéuticas, elementos que a su vez han permitido que cada día más pacientes lleguen a la edad adulta. Pero, es precisamente en este período donde la transición al internista se convierte en una etapa crítica para los pacientes y sus familias (5).

Por ende, aspectos como la incertidumbre por la continuidad del tratamiento, la conciencia de padecer una enfermedad crónica y las limitaciones para integrarse a las diferentes actividades propias de la edad adulta complican esta etapa y a ello, se suma el hecho que durante esta época de la vida, dichos pacientes anhelan independencia y autonomía en la toma de decisiones en lo relacionado con su enfermedad, determinaciones que hasta ese momento habían sido delegadas a sus padres y cuidadores $(5,6)$. En la actualidad el $45 \%$ de los pacientes vinculados a los programas de fibrosis quística en los Estados Unidos, son adultos, que en su mayoría cursan con enfermedad pulmonar grave (6).

Ante ese panorama, esta transición deberá asumirse no como un paso en el manejo, sino como un proceso que puede iniciarse desde los 16 años de vida, en el que se involucre, de manera paulatina en la atención de estos pacientes, a los especialistas de adultos de forma flexible e individualizada. En la literatura acerca del abordaje de la transición del pediatra al internista, el dato más importante que favorece
Neumóloga, Pediatra. Hospital de la Misericordia, Fundación Santa Fé de Bogotá. Bogotá, Colombia.

Correspondencia: Sonia Restrepo. Correo electrónico: sm.restrepo@uniandes. edu.co

Recibido: 15-03-14. Aceptado: 30-03-14. 
este proceso es el conocimiento de la enfermedad por parte de los especialistas en adultos, en cuanto a su diagnóstico, enfoque y estrategias de tratamiento, pues ello permite dar continuidad al manejo de los pacientes. Por esto la buena comunicación entre los centros de atención de fibrosis quística pediátricos y los de adultos, garantizará una transición sin trauma para el paciente y su familia, facilitará posteriormente la adherencia adecuada al manejo con los nuevos especialistas (7), y facilitará la preparación previa para aquellos pacientes que serán candidatos a trasplante pulmonar (8).

En este número de la revista se presenta el caso de un paciente de 22 años con fibrosis quística y hemoptisis, complicación frecuente en los pacientes con la enfermedad. Se revisan, además, la fisiopatología, la clasificación y el abordaje escalonado de esta condición.

Finalmente, invito a todos los especialistas que tendrán a su cargo el tratamiento de pacientes adultos con fibrosis quística, y a aquellos que en algún momento también participarán en su atención, a conocer los planes de tratamiento y manejo, que se han iniciado desde la edad pediátrica, reconociendo de antemano que existen condiciones y complicaciones propias de la enfermedad que aparecen solo durante la edad adulta.

\section{Bibliografía}

1. Ehre C, Ridley C, Thorton D. Review. Cystic fibrosis: An inherited disease affecting mucin-producing organs. Int J Biochem Cell Biol. 2014;52C:136-145.

2. Guía de práctica clínica en el tratamiento del niño con fibrosis quística. Asociación Colombiana de Neumología Pediátrica. 2010. Disponible en: http://issuu.com/acnp/docs/fibrosis_quistica

3. Mateus $\mathrm{H}$, et al. Incidencia estimada de fibrosis quística en la población colombiana. Frecuencia de portadores de la mutación F508del. Grupo de Investigación GeniURos, Escuela de Medicina y Ciencias de la Salud, Bogotá: Universidad del Rosario; 2010.

4. Linsdell P. Cystic fibrosis transmembrane conductance regulator chloride channel blockers: Pharmacological, biophysical and physiological relevance. World J Biol Chem. 2014;5:26-39.

5. Okumura $\mathrm{M}$, et al. Improving transition from paediatric to adult cystic fibrosis care: programme implementation and evaluation. BMJ Qual Saf. 2014;23:i64-i72.

6. Kreindler JL, Miller VA. Cystic fibrosis: addressing the transition from pediatric to adult-oriented health care. Patient Prefer Adherence. 2013;11:1221-6.

7. Smyth A, et al. European cystic fibrosis society standards of care: best practice guidelines. J Cyst Fibros. 2014;13S1:S23-S42.

8. Hirche TO, et al. Practical guidelines: lung transplantation in patients with cystic fibrosis. Pulm Med. 2014;2014:621342. 